\title{
Comments and extensions to EFSUMB guidelines on renal interventional ultrasound (INVUS)
}

\author{
Markus G. Mohaupt ${ }^{1}$, Spyridon Arampatzis', Nathan S. S. Atkinson², Yi Dong ${ }^{3}$, Xin Wu \\ Cui $^{4}$, Andre Ignee ${ }^{5}$, Christoph F. Dietrich ${ }^{5,6}$
}

${ }^{1}$ Department of Nephrology, Hypertension and Clinical Pharmacology, University of Bern, Berne, Switzerland, ${ }^{2}$ Translational Gastroenterology Unit, Oxford University Hospitals NHS Foundation Trust, Oxford, United Kingdom, ${ }^{3}$ Department of Ultrasound, Zhongshan Hospital, Fudan University, 200032 Shanghai, China, ${ }^{4}$ Department of Medical Ultrasound, Tongji Hospital, Tongji Medical College, Huazhong University of Science and Technology, Wuhan, China, ${ }^{5}$ Department of Internal Medicine, Caritas Hospital, Bad Mergentheim, Germany, ${ }^{6}$ Sino-German Research Center of Ultrasound in Medicine, The first affiliated Hospital of Zhengzhou University, China

\begin{abstract}
A substantial evidence base for interventional ultrasound approaches to renal diagnostic sampling and therapeutic access exists. This review comments on the evidence-based recommendations regarding ultrasound-guided renal access which have been published recently within the framework of Guidelines on Interventional Ultrasound (INVUS) of the European Federation of Societies for Ultrasound in Medicine and Biology (EFSUMB) from a clinical practice point of view. Specific aspects of tissue handling and workup, procedural approach and patient interaction are discussed. Indications, contraindications, risk factors and methods to reduce these risks are considered.
\end{abstract}

Keywords: guideline, abscess, cysts, ablation, drainage

\section{Introduction}

Recently the EFSUMB guidelines on interventional ultrasound (INVUS) have been published including information relevant to renal ultrasound [1-9]. The mentioned guidelines are in a series of guidelines [10-15] and comments on guidelines [16-24] published over the last decade. A PubMed search revealed 1560 publications relevant to the topic of renal intervention as of the end of 2015. In addition to the published guidelines, we aim to extend beyond the evidence, with respect to issues incompletely covered by the guidelines, and to provide guidance to clinicians

Received 06.06.2016 Accepted 25.06.2016

Med Ultrason

2016, Vol. 18, No 3, 351-361

Corresponding author: Prof. Dr. med. Christoph F. Dietrich Medizinische Klinik 2, Caritas-Krankenhaus Uhlandstr. 7

D-97980 Bad Mergentheim, Germany

Phone: $(+)$ 49-7931-58 2201

Fax: (+) 49-7931-58 2290

E-mail: christoph.dietrich@ckbm.de from personal experience. As interventional access to the kidney by ultrasound is relevant and used in various conditions including relief of excess fluid in urinary tract obstruction or to obtain histological information, this information should enhance technical knowledge and overall safety. As already indicated in the guidelines, alternative imaging options should be considered frequently, requiring a multidisciplinary decision. An important contributor to overall success is the experience of individual investigators [25].

Indications and contraindications for ultrasound guided interventions are discussed in the EFSUMB guidelines $[7,26]$ for diffuse renal diseases in general, kidney transplant and focal renal lesions. Here we describe background knowledge in more detail.

\section{Description of the intervention including technical issues, specimen preparation, biopsy and cytology for optimal results.}

When employing the EFSUMB guidelines, several procedural aspects deserve to be highlighted and are dis- 
cussed below. As most of these items are based on personal experience and not formally covered by evidence, they should simply support individual decision making.

\section{Issues related to histological workup}

Handling of the tissue sample should be carefully planned, considering the intended result. To allow for light microscopy, immunohistochemical and electron microscopy analyses, additional biopsy cores might be required.

The quality and appropriateness of the sample should be verified immediately following the procedure, both visually and by submerging the sample into $0.9 \%$ saline solution, which helps to differentiate adipose from renal tissue. Experienced investigators will easily distinguish renal tissue from non-renal material. On site review of the sample for adequacy and discussion with a nephropathologist of the workup required improves the diagnostic process.

If renal parenchymal disease is suspected, frozen instantaneous sectioning should be avoided. Rather, prearranging a rapid histological evaluation with a nephropathologist allows a shared initial assessment for sample adequacy and sample apportionment. Such specimens should be provided non-denatured in saline solution within 4-5 hr.

\section{Handling issues related to the intervention}

For native kidney biopsies, when the patient is positioned prone, a mid-abdominal support will be placed. After localising the INVUS target in the positioned patient, the puncture site will be marked, body hair carefully removed, the skin cleaned and skin anesthesia performed. The skin incision should be along the skin folds and allow easy passage of the needle. Through the incision, deep anesthesia is applied in volumes of local anesthetic proportional to the target depth. For renal biopsies 8-10 ml anesthetic will usually be sufficient. As air impairs ultrasound identification of the targets, care should be taken to remove it completely from the syringe. During the biopsy, patient cooperation is extremely important due to kidney movement with respiration. Consequently, caution as to the depth of sedation is necessary. Venous access should be placed and a saline infusion immediately available. A nurse responsible for monitoring tasks throughout the procedure is mandatory. In case of a patient with reduced capability for cooperation, a short anesthestic might be considered to allow an inspiratory ventilation hold whilst performing the biopsy.

Patient positioning must be adapted to provide optimal access for the procedure in a comfortable posture, while allowing the necessary monitoring by assisting personal. As the prone position is favorable for renal biopsies, older or handicapped patients might not tolerate the required posture or intervention time. Thus a test inspiration maneuver demonstrating sufficient duration, should be executed before perfoming the biopsy.

The advantages of a reusable device include its weight, which reduces the repulsion force experience, its dependability, and the calibrated mode of action. On the contrary, the weight poses difficulties in extended procedures on delicate structures, the feather constant of the spring-load system wears and requires recalibration, careful sterilization is required, and loads exceeding the structural limits imposed during handling of the device might interfere with its accuracy. Single-use devices are usually light-weight, and their functionality has been proven. Each user has to individually familiarize himor herself with the repulsion, as handling certainly improves with experience. Fewer complications have been observed with spring-loaded vs. tru-cut needles [27].

Needle length has to be chosen according to the depth of the target region, between 15 and $20 \mathrm{~cm}$ which allows for a small segment of the needle to remain in the needle guide. Either direct measurement or formulas should be applied [28] to predetermine the required needle length. Patients should be warned of potentially frightening noises upon release of the spring-loaded device before employment, to reduce the risk of movement.

Sample size and quality in diffuse renoparenchymal disease has been thoroughly studied. Overall, 14-gauge needles did not improve histological assessment, yet tended to create more complications. Smaller sized needles (16-18 gauge) are sufficient with lower complication rates, while further size reduction compromises histological assessment [29-32].

\section{Access routes - Native kidneys}

Native kidneys are approached from behind in a prone position. In inspiration, the lower pole of the left kidney (see bleeding complications) is the preferred target. The presence of both kidneys should be confirmed and morphological abnormalities requiring special decision making detected. Morphological abnormalities which might not allow a representative tissue collection include kidneys which are malrotated and/or display scars or cysts in the lower pole. Furthermore, biopsies might be complicated by ribs, iliac bone or the absence of perirenal fat tissue in extremely slim patients (see bleeding complications and BMI). In the latter, bowel or large vessels (aorta, caval vein) might be in critical proximity. The kidney should be targeted orthograde.

Measuring the distance from the surface to the target region allows appropriate selection of the needle length. The outer scale on the biopsy gun should be used as a guide. Formulas to calculate the optimal depth of the needle insertion are available and reduce bleeding complications [28]. 
The final positioning of the needle should avoid bending and consecutively high sheer forces between needle and outer cannula. The needle should be advanced half way to the kidney, and while the patient maintains inspiration, be then advanced forward to its final position in front of the kidney. Immediately, the biopsy needle should be released and thereafter the needle withdrawn from the kidney (fig 1).

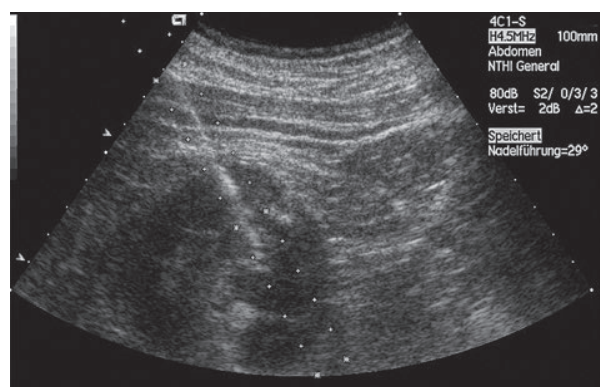

Fig 1. Percutaneous biopsy of a small isoechoic renal lesion $(<12 \mathrm{~mm})$.

If inspiration cannot be maintained, or if the patient continues breathing, the needle must be quickly retracted to a safe position, minimising kidney contact. Otherwise severe laceration injuries can result. This risk is thought to be reduced by performing the procedure during inspiration, as the kidney moves away from the needle when the patient starts breathing. Contrast enhanced ultrasound is helpful in some patients to identify focal lesions and guide the biopsy $[33,34]$. Abscess drainage can be guided using extravascular and intracavitary application of contrast enhanced ultrasound avoiding radiation exposure [4,5,35-37] (fig 2).

CEUS is eastablsiehd to guide radiofrequency ablation. The result with complete (fig 3) or incomplete necrosis can be displayed using CEUS directly after ablation or in the follow up [4,5,24].

\section{Access routes - Transplanted kidneys}

The approach to a transplanted kidney is ventral in a prone patient. The preferred target location is the upper pole, being remote from large vessels and the ureter. Normally, respiration-related movement is limited or absent, yet must be compensated for if present. Access to this pole is sometimes difficult with cranial implantation sites such as the aorta in pediatric transplantation or the common iliac artery, as it might be obstructed by interfering bowel. Sometimes, an enema might resolve access difficulties. Careful exclusion of interfering vessels is required, especially in median positions where the inferior epigastric artery should be positively identified and avoided. Contrast enhanced ultrasound is helpful in some patients to identify focal lesions and guide the biopsy [38].

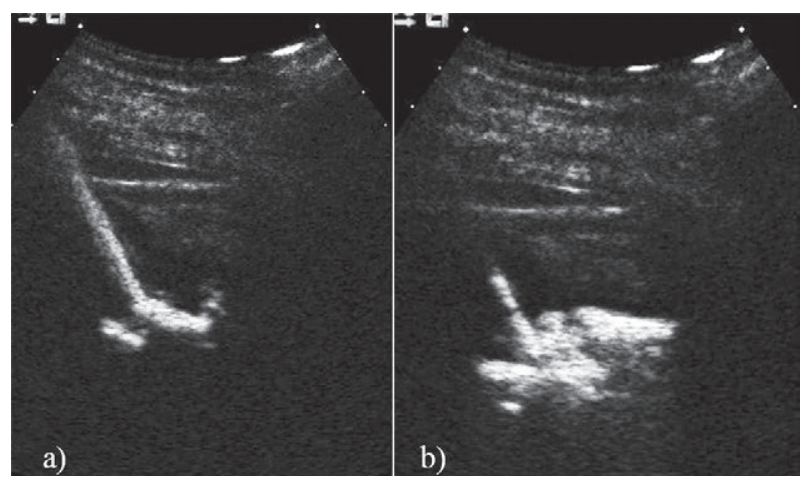

Fig 2. Percutaneous abscess drainage with extravascular and intracavitary application of contrast enhanced ultrasound. The puncture (a) and exclusion of communication (b) are shown.

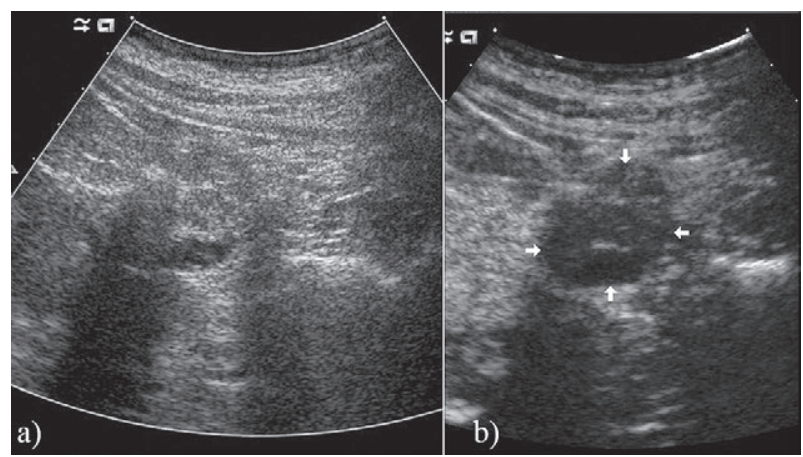

Fig 3. Evaluation of percutaneous radiofrequency thermoablation (RFA) of renal cell carcinoma using B-mode (a) and contrast enhanced ultrasound (b). The total necrosis is shown in (b). No recurrence occurred over the next five years.

\section{Biopsy for parenchymal assessment in renal impairment}

Patient selection:

- Suspected reno-parenchymal disease, particularly glomerular disease.

- Assessment of renal transplants.

Contraindications:

- As discussed in the EFSUMB guidelines $[7,26]$

- Pre- and post-glomerular renal failure (exclusion of pre-renal functional deterioration is complicated and sometimes impossible in renal transplant recipients)

- Severe renovascular disease requiring immediate intervention

\section{Indications:}

Renal biopsies should only be performed if information affecting significant therapeutic consequences can be deduced, which outweighs the potential complications in acute and chronic kidney disease. A nephrologist should be closely involved in the planning of the biopsy and the necessary analyses. Execution of the 
biopsy by a nephrologist is not inferior to a radiologist [39].

\section{Specific symptoms, conditions or kidney diseases requiring renal biopsy:}

Acute renal failure without other recognized causes, particularly in the presence of signs of nephritic glomerular involvement, defines an urgent absolute indication for renal biopsy. Acute renal failure of other causes can often only be unambiguously differentiated from simple prerenal conditions or acute tubular necrosis by renal biopsy. However if signs of nephritis, proteinuria or severe inflammatory involvement are present, renal biopsy should be considered even in the ICU environment.

Beyond this, further indications include: nephrotic range proteinuria, nephritic syndrome, suspected renal involvement in systemic disease (e.g. lupus erythematosus, vasculitis), evaluation of therapeutic response, otherwise unexplained functional loss after renal or other types of transplantation, or suspected drug toxicity due to critical drugs such as calcineurin inhibitors.

In pregnancy, severe acute renal failure and life threatening nephrotic syndrome before the $32^{\text {nd }}$ week of gestation, especially if fetal conditions preclude safe delivery, requires a renal biopsy. Complication rates increase with gestational age and thus biopsy should be postponed until delivery if feasible.

Currently no clear evidence supports the routine use of protocol biopsies following renal transplantation, though protocol biopsies appear to be safe [40].

Contraindications for biopsies of focal lesions and/ or parenchymal disease.

Contraindications to biopsy of focal lesions have not been validated by clinical studies; they are based predominantly on limited evidence, clinical experience, and legal requirements. Absolute and relative contraindications are shown in Table I.

\section{INVUS for nephrostomy insertion; drainage of the collecting system without fluoroscopy}

Percutaneous nephrostomy is performed successfully in $95-98 \%$ of patients with a dilated renal collecting system. It is used to resolve hydronephrosis especially in cases with compromised retrograde transureteral accessibility in obstructive (retroperitoneal fibrosis, tumor or stone disease) or fistulating diseases, and even for diagnostic antegrade pyeloureterography. Bilateral nephrostomies limit quality of life to the extent that unilateral

Table I. Contraindications for biopsies of focal lesions and/or parenchymal disease.

\begin{tabular}{|c|c|}
\hline Absolute contraindications & Relative contraindications \\
\hline $\begin{array}{l}\text { Absent informed consent for the procedure planned except in life } \\
\text { threatening conditions. }\end{array}$ & $\begin{array}{l}\text { Preoperative biopsy of resectable tumors with a high prob- } \\
\text { ability of malignancy especially urothelial cell carcinoma } \\
{[41,42] \text { though biopsy of renal carcinomas does not increase }} \\
\text { rate of metastases nor is bleeding frequently observed [43]. }\end{array}$ \\
\hline Lack of cooperation. & Renal masses exceeding $4 \mathrm{~cm}[44]$. \\
\hline No diagnostic or therapeutical benefit. & Target lesion assumed to have high bleeding risk. \\
\hline Poor needle guidance. & High risk access route (blood vessels, bowel). \\
\hline $\begin{array}{l}\text { Bleeding disorders. } \\
\text { A. Severe plasmatic disorder }[29,45,46] \\
\text { B. Effective oral anticoagulation } \\
\text { C. Inherited or acquired disorders } \\
\text { D. Evaluation should not be based on bleeding time } \\
\text { E. Prolonged PTT indicates higher risk }\end{array}$ & Close proximity to major vessels. \\
\hline Severe thrombocytopenia. & Adrenal masses with suspected pheochromocytoma. \\
\hline $\begin{array}{l}\text { Drugs (low-dose aspirin does increase the risk for mild, yet not } \\
\text { severe complications }[45,47] \text {. }\end{array}$ & Suspected hydatid cyst. \\
\hline $\begin{array}{l}\text { Metabolic disorders (storage diseases such as cystinosis, uremia: } \\
\mathrm{CKD} \geq 4 \text { : danger of HD requirement, increased bleeding risk if } \\
\text { serum creatinine }>196 \mu \mathrm{mol} / \mathrm{l})[31,48,49] \text {. }\end{array}$ & Anomalies of kidney shape and position. \\
\hline $\begin{array}{l}\text { Uncontrolled arterial hypertension (> } 160 \mathrm{mmHg} \text { systolic blood } \\
\text { pressure, }>120 \mathrm{mmHg} \text { mean arterial blood pressure) }[31,49,50] .\end{array}$ & $\begin{array}{l}\text { Biopsy of solitary native kidneys with acceptable risk pos- } \\
\text { sible }[51,52] \text {. }\end{array}$ \\
\hline \multicolumn{2}{|l|}{ Ureteric obstruction with insufficient drainage. } \\
\hline \multicolumn{2}{|l|}{ Acute pyelonephritis. } \\
\hline \multicolumn{2}{|l|}{ Suspected vascular malformation/tumor. } \\
\hline Small kidneys $<9 \mathrm{~cm}$. & \\
\hline Isolated hematuria. & \\
\hline
\end{tabular}


access is usually preferred. Non fluoroscopy-based approaches are the procedure of choice for pregnant women. Contra-indications are similar to other INVUS of the kidney, yet given the prospect to avoid renal replacement therapy, benefit-risk evaluations might differ.

Macroscopic hematuria is frequent, yet significant bleeding is limited to $1-2 \%$, leaving a bleeding-associated mortality of $0.2 \%$. Injury to adjacent organs is infrequent. Septic dissemination of a preexisting pyelonephric infection might occur, whilst de novo contamination during puncturing is recognised. Displacement and obstruction of nephrostomy tubing may develop.

In preparation, the patient is fasted to allow for intubation if required. Intravenous access is placed and blood tests similar to other renal INVUS procedures are applied. The target region is confirmed to be dilated.

Available catheters range from straight short-term polyurethane to pigtail long-term silicone catheters. The patient is approached laterally whilst prone and bent forward, following local anesthesia. The guide wire needle is passed through the posterior inferior calyx at an angle of approximately $30^{\circ}$ to the orthograde plane which should provide easy access to the central pelvis. After dilatation, the catheter is advanced over the guide wire, which is finally removed. Correct position can be confirmed by adding a small amount of contrast media.

Ultrasound guided and contrast enhanced intracavitary approaches have been described for the kidneys and other organs $[35,53,54]$ (fig 4). The first case report was described on the EFSUMB website [www.efusmb.org] and a prospective study has been published [55].

\section{Specific considerations for biopsies}

\section{Role of cytology}

There is only a limited role for fine needle aspirates in renal tumor analysis, as diagnostic certainty is limited; discrimination between benign and malignant lesions is incorrect in up to $60 \%$ of cases [56].

\section{Local anesthesia and intravenous sedation}

Local anesthesia reduces patient discomfort, pain and uncontrolled movements.

Intravenous sedation is discouraged since it might limit the patient's ability to cooperate with respiratory movements and compromise successful intervention.

\section{Infection}

Standard sterile precautions should be applied. The US probe preferably should be cleaned from gel residue and disinfected to the manufacturer's recommendations, as ethanol-based solutions might not be applicable to a given US probe. A sterile probe cover is recommended, yet needs to contain an acoustic coupling medium, preferably sterile gel. The device for puncture guidance should be either sterile single use or thoroughly autoclavable. Antiseptic skin cleaning, a sterile interventional field and instrument table, sterile clothing for the interventionalist, combined with barrier precautions (mask, cap and sterile gloves) has been proposed. Antibiotic prophylaxis is not recommended for renal interventions [57,58].

\section{Blood pressure lowering}

Limited evidence without controlled data suggests calcium channel blockers, clonidine or hydralazine for peri-procedureal blood pressure reduction. Caution should be used as vasodilatation could enhance bleeding $[29,50,59,60]$.

\section{Counselling of complications}

Carefully assessment of risk and appropriate pre-interventional counseling is recommended. The following complications should be discussed with the patient as is appropriate for the clinical scenario.

\section{Organ loss}

The risk of death or overall organ loss, including emergency nephrectomy, is low and lower for INVUS in transplanted as compared to native kidneys $[39,48,61$ $66]$. The risk increases with subcapsular/perirenal hematoma [62].

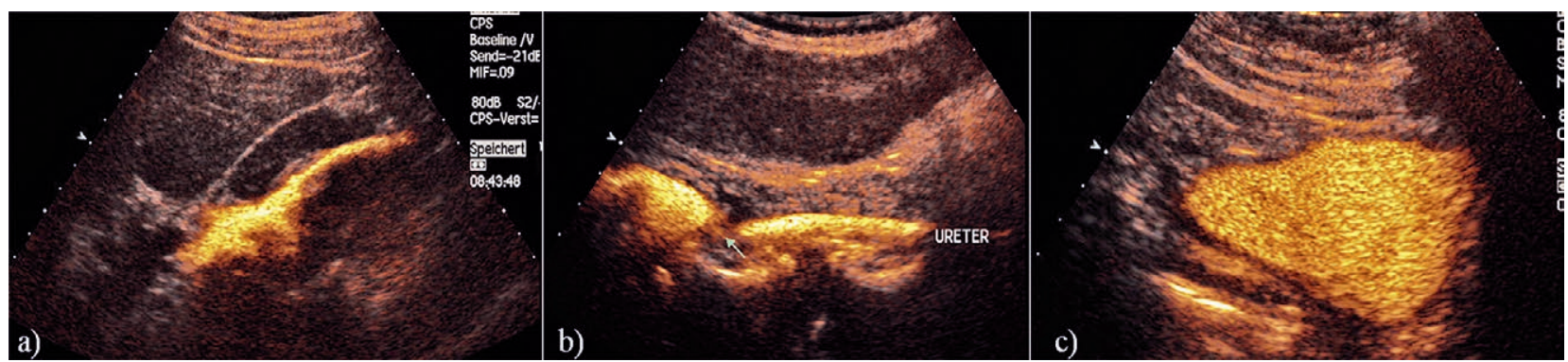

Fig 4. Percutaneous nephrostomy using contrast enhanced ultrasound. The puncture site (a), cause of stenosis (b, arrow) and contrast filled urinary bladder (c) are shown. 


\section{Hemorrhage}

Post-interventional hemorrhage is a serious concern in renal biopsies. Retroperitoneal hematoma should be treated conservatively in most cases. Severe involvement of adjacent organs might require surgical intervention such as compression of the liver with local ischemic damage. Severe bleeding episodes seldom occur in the absence of aspirin [47] and single operators do not further reduce the risk [67].

\section{AV-fistula}

AV-fistula frequently occurs after biopsy, particularly in renal grafts, with a high rate of spontaneous closure $[52,68]$. Three dimensional imaging might improve identification of the feeder morphology [69]. Interventional embolization and coiling of the feeder vessel or the aneurysm itself are rarely required. Malignant conversion with total or partial organ loss, is rare [25,66,70-81].

\section{Infectious complications}

If aseptic procedures are followed thoroughly, with special emphasis in immunocompromised patients, infectious complications are rare. Yet severe infections including urosepsis, perirenal abscess formation and skin infiltration might be observed.

\section{Rare complications}

Further rare complications include hydronephrosis, bladder tamponade, renal functional impairment, pneumothorax and other tissue lesions [41,42,48,82-84].

\section{Needle tract seeding of malignant tumors}

The risk of renal cell carcinoma seeding after fine needle puncture or nephrostomy is described only in case reports. While data indicate a clinically significance risk for liver tumor biopsies, it is almost negligible in renal cancers $[85,86]$.

\section{Management of complications}

\section{Prevention}

Risk assessment and patient selection for INVUS:

1. A rigorous assessment should be undertaken with respect to the expected overall benefit, the procedural risk, the timeline and potential alternative approaches

2. When interpreting the risk for a patient, the conditions specified in the section on bleeding complications above need to be considered, as platelet count or INR may be insufficient. Notably, the clinical bleeding history should also be considered in decision making [87].

3 . The risk of interrupting antiplatelet or conventional anticoagulant therapy needs to be stratified according to the clinical condition. NOACs, which are also not reflected by the global function tests, need to be considered.

\section{Bleeding risk modification and risk reduction techniques}

Bleeding risk factor modification and risk reduction techniques should be undertaken as per current anticoagulation guidelines. The risk of bleeding should be weighed against the risk of changing the anticoagulation treatment. Conditions without an increased bleeding risk include monoclonal gammopathies [88], diabetes mellitus [89], pediatric kidneys in most reports [90-93] and outpatients [94,95]. For advanced guidance, bleeding risk predictors are summarized in Table II.

Table II. Prediction of increased bleeding risk after percutaneous renal biopsies.

1. Disturbed cellular or plasmatic hemostasis

a. Platelet count and INR [50,96]

b. Platelet dysfunction such as in uremia or storage disease $[97,98]$

2. Arterial hypertension $[49,50]$

3. Type of renal affection

a. Systemic infectious and storage diseases including hepatitis C infection, HIV, amyloidosis and cystinosis [50,96]

b. Renal diseases including thin basement membrane syndrome, vasculitis, rapidly progressive glomerulonephritis or acute interstitial nephritis [89]

c. Acute renal failure [31] though this is not confirmed in smaller studies

d. Severe, chronic renal functional impairment [31,89]

4. Number of needle passes [31]

5. Female gender $[31,72,99]$

6. Glucocorticoid therapy [31]

7. Age [31]

8. Low resource settings [100]

9. Right kidneys [72]

10. Lower BMI [72]

11. Lower blood pressure in renal transplantation [72]

12. High blood pressure, systolic $>170 \mathrm{mmHg}$ [63]

13. Renal grafts tend to demonstrate more hematuria [101], yet less overall hemorrhage $[25,29,48,63,81,102-104]$ 


\section{Follow-up strategies to reduce complications}

\section{Post biopsy strategies to reduce complications}

1. Post-intervention, thorough compression of the biopsy area is performed before placing the patient on a sandbag for native, or a sandbag on the kidney for transplanted kidneys, for at least 4 hrs (nevertheless there is no evidence to do so).

2. Surveillance should be adapted to the patient's risk profile according to ASA criteria. Intermediate or ICU facilities should be available on demand.

3. Day care might be appropriate for selected low risk patients, if no periprocedural bleeding occurs [89].

\section{Follow up}

- Post-intervention US scanning is recommended to identify fluid collections, hematoma or persistent needle track flow ("patent track") by color duplex. Immediate hematoma formation after percutaneous renal biopsy predicts clinically significant bleeding complications [104, 105].

- If clinical deterioration suggests persistent bleeding, repeat US supplemented by CEUS should be applied [106].

- Given most bleeding complications in native kidneys and renal transplants occur within the first 8 hrs after INVUS, bed rest should be mandated during this period $[47,48,62,99,107-109]$.
- Bleeding complications are unlikely, if the following applies:

- Absence of hematoma $1 \mathrm{~h}$ after biopsy at US [104] and significant bleeding causing clinical signs is absent after $18 \mathrm{hrs}$ [50].

- A hematoma is present but $<2 \mathrm{~cm}$ [84] and no hematocrit changes occur within the first 6 hrs [110,111].

- The patient should be educated on what action to take and how to access supportive care in an emergency.

- Extended postprocedural monitoring has not been proven beneficial.

We developed a procedural guideline for outpatient biopsies based on the guidelines and above comments. Patients qualify as having a low risk for renal biopsyrelated complications and conversion into a high risk condition if the following conditions apply (Table III).

\section{Conclusion}

Renal INVUS for diagnostic and therapeutic purposes play a valuable role in nephrology supported by a broad evidence base. Aspects of the procedure technique are amenable to optimization, particularly handling of histological tissue, patent preparation, approach and preprocedural risk identification. Bleeding risk modification and post-interventional strategies minimise patient harm

Table III. Patients with low risk renal biopsies and controlling low-high risk converting conditions.

Low risk for renal biopsy

Cooperative.

Absence of inborn or acquired plasma or cellular bleeding disorders, aspirin is discontinued.

Absence of storage disease and uremia $(C K D \geq 4)$ (diabetes mellitus and monoclonal gammopathies do not per se manifest a high risk).

Serum creatinine $<196 \mathrm{umol} / 1$ or acute renal injury.

Blood pressure $<100 \mathrm{mmHg}$ diastolic and $<160 / 170 \mathrm{mmHg}$ systolic and mean between $60-120 \mathrm{mmHg}$.

Absence of ureteral obstruction or dilated renal pelvis.
Low-high risk converting conditions

Biopsy of a right kidney

Duplex mode unavailable during the procedure.

Use of calcium channel blockers, clonidine or hydralazine for blood pressure control.

Not calculating optimal depth of insertion (body weight $[\mathrm{kgX10}] /$ body height $[\mathrm{cm}])-0.5=$ depth $[\mathrm{cm}]$ ) for native kidneys prior to biopsy.

Requirement of $\geq 3$ needle passes.

Hematoma on ultrasound evaluation within the first hour post biopsy (especially $>2 \mathrm{~cm}$ ).

Decreasing hematocrit 6 hours post biopsy.

Absence of acute pyelonephritis.

Absence of suspicion for vascular malformation/tumor.

Kidney length $>9 \mathrm{~cm}$.

Absence of isolated hematuria.

No high risk access route.

Biopsy site not in close proximity to major vessels.

Absence of anomalies of kidney shape and position.

$\mathrm{BMI} \geq 18 \mathrm{~kg} / \mathrm{m}^{2}$. 
when combined with EFSUMB guideline recommendations. Further clinical studies are still required to optimize several aspects of renal INVUS. For further illustrating images we refer to the textbook $[112,113]$ and the EFSUMB website (www.efsumb.org).

\section{Conflict of interest: none}

\section{References}

1. Jenssen C, Brkljacic B, Hocke M, et al. EFSUMB Guidelines on Interventional Ultrasound (INVUS), Part VI. Ultraschall Med 2015. doi: 10.1055/s-0035-1566900.

2. Fusaroli P, Jenssen C, Hocke M, et al. EFSUMB Guidelines on Interventional Ultrasound (INVUS), Part V. Ultraschall Med 2015. doi: 10.1055/s-0035-1553738.

3. Jenssen C, Hocke M, Fusaroli P, et al. EFSUMB Guidelines on Interventional Ultrasound (INVUS), Part IV - EUSguided Interventions: General aspects and EUS-guided sampling (Long Version). Ultraschall Med 2016; 37: E33E76.

4. Dietrich CF, Lorentzen T, Appelbaum L, et al. EFSUMB Guidelines on Interventional Ultrasound (INVUS), Part III - Abdominal Treatment Procedures (Short Version). Ultraschall Med 2016; 37: 27-45.

5. Dietrich CF, Lorentzen T, Appelbaum L, et al. EFSUMB Guidelines on Interventional Ultrasound (INVUS), Part III - Abdominal Treatment Procedures (Long Version). Ultraschall Med 2016; 37: E1-E32.

6. Sidhu PS, Brabrand K, Cantisani V, et al. EFSUMB Guidelines on Interventional Ultrasound (INVUS), Part II. Ultraschall Med 2015; 36: E15-35.

7. Sidhu PS, Brabrand K, Cantisani V, et al. EFSUMB Guidelines on Interventional Ultrasound (INVUS), Part II. Ultraschall Med 2015; 36: 566-580.

8. Lorentzen T, Nolsoe CP, Ewertsen C, et al. EFSUMB Guidelines on Interventional Ultrasound (INVUS), Part I. General Aspects (Short Version). Ultraschall Med 2015; 36 : 464-472.

9. Lorentzen T, Nolsoe CP, Ewertsen C, et al. EFSUMB Guidelines on Interventional Ultrasound (INVUS), Part I. General Aspects (long Version). Ultraschall Med 2015; 36: E1-E14.

10. Claudon M, Dietrich CF, Choi BI, et al. Guidelines and good clinical practice recommendations for contrast enhanced ultrasound (CEUS) in the liver--update 2012: a WFUMBEFSUMB initiative in cooperation with representatives of AFSUMB, AIUM, ASUM, FLAUS and ICUS. Ultraschall Med 2013; 34: 11-29.

11. Claudon M, Dietrich CF, Choi BI, et al. Guidelines and good clinical practice recommendations for Contrast Enhanced Ultrasound (CEUS) in the liver - update 2012: A WFUMB-EFSUMB initiative in cooperation with representatives of AFSUMB, AIUM, ASUM, FLAUS and ICUS. Ultrasound Med Biol 2013; 39: 187-210.
12. Piscaglia F, Nolsoe C, Dietrich CF, et al. The EFSUMB Guidelines and Recommendations on the Clinical Practice of Contrast Enhanced Ultrasound (CEUS): update 2011 on non-hepatic applications. Ultraschall Med 2012; 33: 33-59.

13. Dietrich CF, Averkiou MA, Correas JM, Lassau N, Leen E, Piscaglia F. An EFSUMB introduction into Dynamic Contrast-Enhanced Ultrasound (DCE-US) for quantification of tumour perfusion. Ultraschall Med 2012; 33: 344-351.

14. Cosgrove D, Piscaglia F, Bamber J, et al. EFSUMB guidelines and recommendations on the clinical use of ultrasound elastography. Part 2: Clinical applications. Ultraschall Med 2013; 34: 238-253.

15. Bamber J, Cosgrove D, Dietrich CF, et al. EFSUMB guidelines and recommendations on the clinical use of ultrasound elastography. Part 1: Basic principles and technology. U1traschall Med 2013; 34: 169-184.

16. Cui XW, Friedrich-Rust M, De Molo C, Ignee A, SchreiberDietrich D, Dietrich CF. Liver elastography, comments on EFSUMB elastography guidelines 2013. World J Gastroenterol 2013; 19: 6329-6347.

17. Dietrich CF, Chiorean L, Potthoff A, Ignee A, Cui X, Sparchez Z. Percutaneous sclerotherapy of liver and renal cysts, comments on the EFSUMB guidelines. Z Gastroenterol 2016; 54: 155-166.

18. Dietrich CF. EFSUMB guidelines 2015 on interventional ultrasound. Med Ultrason 2015; 17: 521-527.

19. Dietrich CF, Cui XW, Schreiber-Dietrich DG, Ignee A. EFSUMB guidelines 2011: comments and illustrations. Ultraschall Med 2012; 33 Suppl 1: S11-S21.

20. Dietrich CF, Cui XW, Barreiros AP, Hocke M, Ignee A. EFSUMB guidelines 2011: comment on emergent indications and visions. Ultraschall Med 2012;33 Suppl 1: S39-S47.

21. Dietrich CF, Cui XW, Boozari B, Hocke M, Ignee A. Contrast-enhanced ultrasound (CEUS) in the diagnostic algorithm of hepatocellular and cholangiocellular carcinoma, comments on the AASLD guidelines. Ultraschall Med 2012; 33 Suppl 1: S57-S66.

22. Barreiros AP, Piscaglia F, Dietrich CF. Contrast enhanced ultrasound for the diagnosis of hepatocellular carcinoma (HCC): comments on AASLD guidelines. J Hepatol 2012; 57: 930-932.

23. Dietrich CF, Schreiber-Dietrich D, Hocke M. Comments on the EFSUMB non-liver Guidelines 2011. Praxis (Bern 1994) 2012; 101: 1175-1181.

24. Dietrich CF, Cui XW, Chiorean L, Appelbaum L, Leen E, Ignee A. Local ablative procedures of the liver. Z Gastroenterol 2015; 53: 579-590.

25. Hergesell O, Felten H, Andrassy K, Kuhn K, Ritz E. Safety of ultrasound-guided percutaneous renal biopsy-retrospective analysis of 1090 consecutive cases. Nephrol Dial Transplant 1998; 13: 975-977.

26. Cantisani V, David E, Meloni FM, et al. Recall strategies for patients found to have a nodule in cirrhosis: is there still a role for CEUS? Med Ultrason 2015; 17: 515-520.

27. Kovalik EC, Schwab SJ, Gunnells JC, Bowie D, Smith SR. No change in complication rate using spring-loaded gun 
compared to traditional percutaneous renal allograft biopsy techniques. Clin Nephrol 1996; 45: 383-385.

28. Pasquariello A, Innocenti M, Batini V, et al. Theoretical calculation of optimal depth in the percutaneous native kidney biopsy to drastically reduce bleeding complications and sample inadequacy for histopathological diagnosis. Nephrol Dial Transplant 2007; 22: 3516-3520.

29. Manno C, Strippoli GF, Arnesano L, et al. Predictors of bleeding complications in percutaneous ultrasound-guided renal biopsy. Kidney Int 2004; 66: 1570-1577.

30. Nicholson ML, Wheatley TJ, Doughman TM, et al. A prospective randomized trial of three different sizes of corecutting needle for renal transplant biopsy. Kidney Int 2000; 58: 390-395.

31. Corapi KM, Chen JL, Balk EM, Gordon CE. Bleeding complications of native kidney biopsy: a systematic review and meta-analysis. Am J Kidney Dis 2012; 60: 62-73.

32. Roth R, Parikh S, Makey D, et al. When size matters: diagnostic value of kidney biopsy according to the gauge of the biopsy needle. Am J Nephrol 2013; 37: 249-254.

33. Ignee A, Straub B, Brix D, Schuessler G, Ott M, Dietrich $\mathrm{CF}$. The value of contrast enhanced ultrasound (CEUS) in the characterisation of patients with renal masses. Clin Hemorheol Microcirc 2010; 46: 275-290.

34. Ignee A, Straub B, Schuessler G, Dietrich CF. Contrast enhanced ultrasound of renal masses. World J Radiol 2010; 2: $15-31$.

35. Ignee A, Jenssen C, Cui XW, Schuessler G, Dietrich CF. Intracavitary contrast-enhanced ultrasound in abscess drainage--feasibility and clinical value. Scand J Gastroenterol 2016; 51: 41-47.

36. Gottschalk U, Ignee A, Dietrich CF. Ultrasound guided interventions, part 1, diagnostic procedures. Z Gastroenterol 2009; 47: 682-690.

37. Gottschalk U, Ignee A, Dietrich CF. Ultrasound-guided interventions and description of the equipment. Z Gastroenterol 2010; 48: 1305-1316.

38. Ignee A, Hocke M, Selbach J, Cui XW, Woenckhaus M, Dietrich CF. Papillary renal cell carcinoma in the transplanted kidney - a case report focusing on contrast enhanced ultrasound features. Med Ultrason 2012; 14: 246-250.

39. Chung S, Koh ES, Kim SJ, et al. Safety and tissue yield for percutaneous native kidney biopsy according to practitioner and ultrasound technique. BMC Nephrol 2014; 15: 96.

40. Furness PN, Philpott CM, Chorbadjian MT, et al. Protocol biopsy of the stable renal transplant: a multicenter study of methods and complication rates. Transplantation 2003;76:969-973.

41. Remzi M, Marberger M. Renal tumor biopsies for evaluation of small renal tumors: why, in whom, and how? Eur Urol 2009; 55: 359-367.

42. Volpe A, Kachura JR, Geddie WR, et al. Techniques, safety and accuracy of sampling of renal tumors by fine needle aspiration and core biopsy. J Urol 2007; 178: 379-386.

43. Somani BK, Nabi G, Thorpe P, et al. Image-guided biopsydiagnosed renal cell carcinoma: critical appraisal of technique and long-term follow-up. Eur Urol 2007; 51: 1289-1295.
44. Leveridge MJ, Finelli A, Kachura JR, et al. Outcomes of small renal mass needle core biopsy, nondiagnostic percutaneous biopsy, and the role of repeat biopsy. Eur Urol 2011; 60: 578-584.

45. Mackinnon B, Fraser E, Simpson K, Fox JG, Geddes C. Is it necessary to stop antiplatelet agents before a native renal biopsy? Nephrol Dial Transplant 2008; 23: 3566-3570.

46. van den Hoogen MW, Verbruggen BW, Polenewen R, Hilbrands LB, Novakova IR. Use of the platelet function analyzer to minimize bleeding complications after renal biopsy. Thromb Res 2009; 123: 515-522.

47. Atwell TD, Smith RL, Hesley GK, et al. Incidence of bleeding after 15,181 percutaneous biopsies and the role of aspirin. AJR Am J Roentgenol 2010; 194: 784-789.

48. Whittier WL, Korbet SM. Timing of complications in percutaneous renal biopsy. J Am Soc Nephrol 2004; 15: 142-147.

49. Shidham GB, Siddiqi N, Beres JA, et al. Clinical risk factors associated with bleeding after native kidney biopsy. Nephrology (Carlton) 2005; 10: 305-310.

50. Eiro M, Katoh T, Watanabe T. Risk factors for bleeding complications in percutaneous renal biopsy. Clin Exp Nephrol 2005; 9: 40-45.

51. Fuiano G, Mazza G, Comi N, et al. Current indications for renal biopsy: a questionnaire-based survey. Am J Kidney Dis 2000; 35: 448-457.

52. Stiles KP, Yuan CM, Chung EM, Lyon RD, Lane JD, Abbott KC. Renal biopsy in high-risk patients with medical diseases of the kidney. Am J Kidney Dis 2000; 36: 419-433.

53. Ignee A, Cui X, Schuessler G, Dietrich CF. Percutaneous transhepatic cholangiography and drainage using extravascular contrast enhanced ultrasound. Z Gastroenterol 2015; 53: 385-390.

54. Ignee A, Schuessler G, Cui XW, Dietrich CF. Intracavitary contrast medium ultrasound - different applications, a review of the literature ad future prospects. Ultraschall Med 2013; 34: 504-525.

55. Cui XW, Ignee A, Maros T, Straub B, Wen JG, Dietrich CF. Feasibility and usefulness of intracavitary contrast enhanced ultrasound in percutaneous nephrostomy. Ultrasound Med Biol 2016. doi: 10.1016/j.ultrasmedbio.2016.04.015.

56. Young NA, Mody DR, Davey DD. Misinterpretation of normal cellular elements in fine-needle aspiration biopsy specimens: observations from the College of American Pathologists Interlaboratory Comparison Program in NonGynecologic Cytopathology. Arch Pathol Lab Med 2002; 126: 670-675.

57. Winter TC, Lee FT Jr, Hinshaw JL. Ultrasound-guided biopsies in the abdomen and pelvis. Ultrasound Q 2008; 24: 45-68.

58. Nolsoe CP, Lorentzen T, Skjoldbye BO, Bachmann Nielsen $\mathrm{M}$. The basics of interventional ultrasound. Ultraschall Med 2007; 28: 248-263.

59. Maya ID, Allon M. Percutaneous renal biopsy: outpatient observation without hospitalization is safe. Semin Dial 2009; 22: 458-461.

60. Kohli HS, Jairam A, Bhat A, et al. Safety of kidney biopsy in elderly: a prospective study. Int Urol Nephrol 2006; 38 : 815-820. 
61. Preda A, Van Dijk LC, Van Oostaijen JA, Pattynama PM. Complication rate and diagnostic yield of 515 consecutive ultrasound-guided biopsies of renal allografts and native kidneys using a 14-gauge Biopty gun. Eur Radiol 2003; 13: 527-530.

62. Korbet SM. Percutaneous renal biopsy. Semin Nephrol 2002; 22: 254-267.

63. Korbet SM, Volpini KC, Whittier WL. Percutaneous renal biopsy of native kidneys: a single-center experience of 1,055 biopsies. Am J Nephrol 2014; 39: 153-162.

64. Tondel C, Vikse BE, Bostad L, Svarstad E. Safety and complications of percutaneous kidney biopsies in 715 children and 8573 adults in Norway 1988-2010. Clin J Am Soc Nephrol 2012; 7: 1591-1597.

65. Whittier WL. Complications of the percutaneous kidney biopsy. Adv Chronic Kidney Dis 2012; 19: 179-187.

66. Mendelssohn DC, Cole EH. Outcomes of percutaneous kidney biopsy, including those of solitary native kidneys. Am J Kidney Dis 1995; 26: 580-585.

67. Tang S, Li JH, Lui SL, Chan TM, Cheng IK, Lai KN. Freehand, ultrasound-guided percutaneous renal biopsy: experience from a single operator. Eur J Radiol 2002; 41: 65-69.

68. Merkus JW, Zeebregts CJ, Hoitsma AJ, van Asten WN, Koene RA, Skotnicki SH. High incidence of arteriovenous fistula after biopsy of kidney allografts. Br J Surg 1993; 80: 310-312.

69. Mohaupt MG, Perrig M, Vogt B. 3D Ultrasound imaging--a useful non-invasive tool to detect AV fistulas in transplanted kidneys. Nephrol Dial Transplant 1999; 14: 940-943.

70. Fossaceca R, Guzzardi G, Cerini P, et al. Management of postbiopsy arteriovenous fistulas in transplanted kidneys and effectiveness of endovascular treatment: a single-center experience. Ann Vasc Surg 2014; 28: 452-456.

71. Ierardi AM, Floridi C, Fontana F, et al. Transcatheter embolisation of iatrogenic renal vascular injuries. Radiol Med 2014; 119: 261-268.

72. Peters B, Andersson Y, Stegmayr B, et al. A study of clinical complications and risk factors in 1,001 native and transplant kidney biopsies in Sweden. Acta Radiol 2014; 55: 890-896.

73. Gulcu A, Goktay Y, Soylu A, et al. Doppler US evaluation of renal biopsy complications in children. Diagn Interv Radiol 2013; 19: 15-19.

74. Loffroy R, Guiu B, Lambert A, et al. Management of postbiopsy renal allograft arteriovenous fistulas with selective arterial embolization: immediate and long-term outcomes. Clin Radiol 2008; 63: 657-665.

75. Schwarz A, Hiss M, Gwinner W, Becker T, Haller H, Keberle M. Course and relevance of arteriovenous fistulas after renal transplant biopsies. Am J Transplant 2008; 8: 826-831.

76. Maleux G, Messiaen T, Stockx L, Vanrenterghem Y, Wilms G. Transcatheter embolization of biopsy-related vascular injuries in renal allografts. Long-term technical, clinical and biochemical results. Acta Radiol 2003; 44: 13-17.

77. Perini S, Gordon RL, LaBerge JM, et al. Transcatheter embolization of biopsy-related vascular injury in the transplant kidney: immediate and long-term outcome. J Vasc Interv Radiol 1998; 9: 1011-1019.

78. Deane C, Cowan N, Giles J, et al. Arteriovenous fistulas in renal transplants: color Doppler ultrasound observations. Urol Radiol 1992; 13: 211-217.

79. Hubsch PJ, Mostbeck G, Barton PP, et al. Evaluation of arteriovenous fistulas and pseudoaneurysms in renal allografts following percutaneous needle biopsy. Color-coded Doppler sonography versus duplex Doppler sonography. J Ultrasound Med 1990; 9: 95-100.

80. Riehl J, Maigatter S, Kierdorf H, Schmitt H, Maurin N, Sieberth HG. Percutaneous renal biopsy: comparison of manual and automated puncture techniques with native and transplanted kidneys. Nephrol Dial Transplant 1994; 9: 1568-1574.

81. Meola M, Barsotti G, Cupisti A, Buoncristiani E, Giovannetti S. Free-hand ultrasound-guided renal biopsy: report of 650 consecutive cases. Nephron 1994; 67: 425-430.

82. Lefaucheur C, Nochy D, Bariety J. Renal biopsy: procedures, contraindications, complications. Nephrol Ther 2009; 5: 331-339.

83. Walker PD. The renal biopsy. Arch Pathol Lab Med 2009; 133: 181-188.

84. Uppot RN, Harisinghani MG, Gervais DA. Imaging-guided percutaneous renal biopsy: rationale and approach. AJR Am J Roentgenol 2010; 194: 1443-1449.

85 . Herts BR. Imaging guided biopsies of renal masses. Curr Opin Urol 2000; 10: 105-109.

86. Robertson EG, Baxter G. Tumour seeding following percutaneous needle biopsy: The real story! Clin Radiol 2013; 66: 1007-1014.

87. Chiorean L, Barr RG, Braden B, et al. Transcutaneous U1trasound: Elastographic Lymph Node Evaluation. Current Clinical Applications and Literature Review. Ultrasound Med Biol 2016; 42: 16-30.

88. Fish R, Pinney J, Jain P, et al. The incidence of major hemorrhagic complications after renal biopsies in patients with monoclonal gammopathies. Clin J Am Soc Nephrol 2010; 5: 1977-1980.

89. Fisi V, Mazak I, Degrell P, et al. Histological diagnosis determines complications of percutaneous renal biopsy: a single-center experience in 353 patients. Kidney Blood Press Res 2012; 35: 26-34.

90. Rianthavorn P, Kerr SJ, Chiengthong K. Safety of paediatric percutaneous native kidney biopsy and factors predicting bleeding complications. Nephrology (Carlton) 2014; 19: $143-148$

91. Hirano D, Fujinaga S, Nishizaki N, Kanai H, Ida H. Role of ultrasound in revealing complications following percutaneous renal biopsy in children. Clin Nephrol 2013; 80: 426-432.

92. Sumboonnanonda A, Srajai K, Vongjirad A, Suntornpoch V, Parichatikanond P. Percutaneous renal biopsy in children. J Med Assoc Thai 2002; 85 Suppl 2: S755-S761.

93. Skalova S, Rejtar P. Safety profile of paediatric percutaneous ultrasonography-guided renal biopsies. Singapore Med J 2010; 51: 481-483. 
94. Lin WC, Yang Y, Wen YK, Chang CC. Outpatient versus inpatient renal biopsy: a retrospective study. Clin Nephrol 2006; 66: 17-24.

95. Fraser IR, Fairley KF. Renal biopsy as an outpatient procedure. Am J Kidney Dis 1995; 25: 876-878.

96. Chiorean L, Cantisani V, Jenssen C, Sidhu PS, Baum U, Dietrich CF. Focal masses in a non-cirrhotic liver: The additional benefit of CEUS over baseline imaging. Eur J Radiol 2015; 84: 1636-1643.

97. Chiorean L, Caraiani C, Radzina M, Jedrzejczyk M, Schreiber-Dietrich D, Dietrich CF. Vascular phases in imaging and their role in focal liver lesions assessment. Clin Hemorheol Microcirc 2015; 62: 299-326.

98. Chiorean L, Cui XW, Tannapfel A, et al. Benign liver tumors in pediatric patients - Review with emphasis on imaging features. World J Gastroenterol 2015; 21: 85418561.

99. Mishra A, Tarsin R, Elhabbash B, et al. Percutaneous ultrasound-guided renal biopsy: A Libyan experience. Indian J Nephrol 2010; 20: 76-79.

100. al Rasheed SA, al Mugeiren MM, Abdurrahman MB, Elidrissy AT. The outcome of percutaneous renal biopsy in children: an analysis of 120 consecutive cases. Pediatr Nephrol 1990; 4: 600-603.

101. Gainza FJ, Minguela I, Lopez-Vidaur I, Ruiz LM, Lampreabe I. Evaluation of complications due to percutaneous renal biopsy in allografts and native kidneys with colorcoded Doppler sonography. Clin Nephrol 1995; 43: 303308.

102. Beckingham IJ, Nicholson ML, Bell PR. Analysis of factors associated with complications following renal transplant needle core biopsy. Br J Urol 1994; 73: 13-15.
103. Boschiero LB, Saggin P, Galante O, et al. Renal needle biopsy of the transplant kidney: vascular and urologic complications. Urol Int 1992; 48: 130-133.

104. Waldo B, Korbet SM, Freimanis MG, Lewis EJ. The value of post-biopsy ultrasound in predicting complications after percutaneous renal biopsy of native kidneys. Nephrol Dial Transplant 2009; 24: 2433-2439.

105. Ishikawa E, Nomura S, Hamaguchi T, et al. Ultrasonography as a predictor of overt bleeding after renal biopsy. Clin Exp Nephrol 2009; 13: 325-331.

106. Catalano O, Cusati B, Nunziata A, Siani A. Active abdominal bleeding: contrast-enhanced sonography. Abdom Imaging 2006; 31: 9-16.

107. Jiang SH, Karpe KM, Talaulikar GS. Safety and predictors of complications of renal biopsy in the outpatient setting. Clin Nephrol 2011; 76: 464-469.

108. Marwah DS, Korbet SM. Timing of complications in percutaneous renal biopsy: what is the optimal period of observation? Am J Kidney Dis 1996; 28: 47-52.

109. Yablon Z, Recupero P, McKenna J, Vella J, Parker MG. Kidney allograft biopsy: timing to complications. Clin Nephrol 2010; 74: 39-45.

110. Daram SR, Reddivari V, Bastani B. Bleeding complications associated with percutaneous renal biopsy using Biopince(R) needle. Int Urol Nephrol 2010; 42: 841-842.

111. Sethi I, Brier M, Dwyer A. Predicting post renal biopsy complications. Semin Dial 2013; 26: 633-635.

112. Dietrich CF, Nuernberg D. Interventional ultrasound. A practical guide and atlas. Thieme, 2014.

113. Dietrich CF, Nuernberg D. Interventioneller Ultraschall. Lehrbuch und Atlas für die interventionelle Sonographie. Thieme Verlag, 2011. 